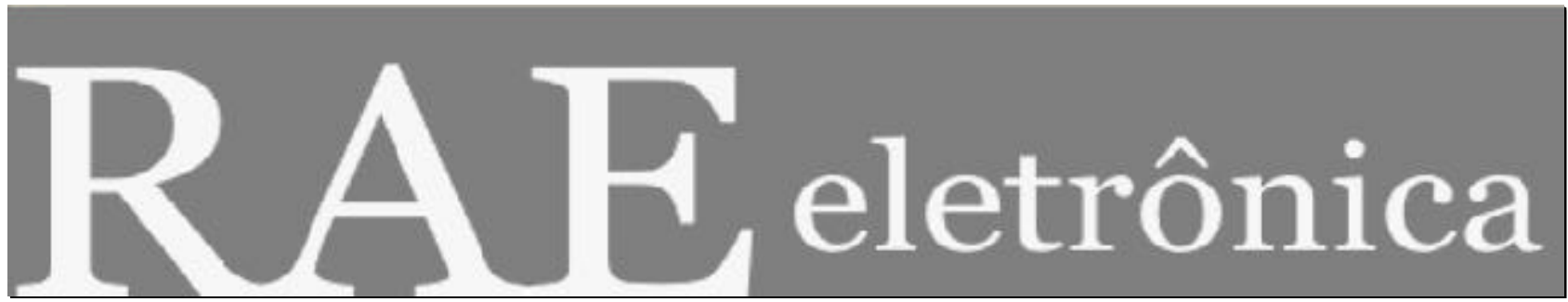

\title{
AVALIAÇÃo DA GESTÃo DE PROGRAMAS DE QUALIDADE DE VIDA NO TRABALHO
}

Por:

\section{Patrícia Morilha de Oliveira Ana Cristina Limongi-França}

RAE-eletrônica, v. 4, n. 1, Art. 9, jan./jul. 2005

http://www.rae.com.br/eletronica/index.cfm?FuseAction=Artigo \&ID=2209\&Secao=ARTIGOS\&Volu $\mathrm{me}=4 \&$ Numero $=1 \& \mathrm{Ano}=2005$

CCopyright, 2005, RAE-eletrônica. Todos os direitos, inclusive de tradução, são reservados. É permitido citar parte de artigos sem autorização prévia desde que seja identificada a fonte. A reprodução total de artigos é proibida. Os artigos só devem ser usados para uso pessoal e nãocomercial. Em caso de dúvidas, consulte a redação: raeredacao@fgvsp.br.

A RAE-eletrônica é a revista on-line da FGV-EAESP, totalmente aberta e criada com o objetivo de agilizar a veiculação de trabalhos inéditos. Lançada em janeiro de 2002, com perfil acadêmico, é dedicada a professores, pesquisadores e estudantes. Para mais informações consulte o site www.rae.com.br/eletronica.

\section{RAE-eletrônica}

ISSN 1676-5648

(C2005 Fundação Getulio Vargas - Escola de Administração de Empresas de São Paulo.

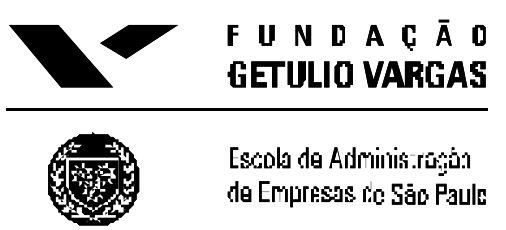




\title{
RESUMO
}

A avaliação dos resultados de Gestão de Pessoas é hoje um dos temas mais desafiadores para esta área e que vem recebendo investimentos cada vez maiores. Nas questões relacionadas à Gestão dos Programas de Qualidade de Vida no Trabalho, muitas expectativas de resultados são levantadas: melhor percepção de bem-estar para as pessoas, o que influencia direta ou indiretamente na produtividade e nos resultados financeiros da Organização. Este artigo trata da percepção dos administradores sobre a possibilidade de se avaliar os resultados da Gestão de QVT, com base na pesquisa quantitativa sobre os fatores críticos de gestão. Acrescenta resultados de estudo de caso de uma empresa que pratica a avaliação dos resultados, mostrando seus indicadores para QVT. A partir deste conjunto de estudos, ratifica-se a necessidade de difusão de práticas para avaliação de resultados, e ainda, que tal avaliação pode ser feita de maneira clara, por meio de indicadores. O caso também demonstra que estas ferramentas auxiliam os profissionais a gerir a qualidade dos programas desenvolvidos.

\section{PALAVRAS-CHAVE}

Gestão de pessoas, gestão da qualidade de vida no trabalho (GQVT), mensuração de resultados empresariais, avaliação de resultados.

\begin{abstract}
The evaluation of the results of People Management programs represents one of the most challenging subjects for study in this field today, as the it has received increasing investments in many companies. Considering the Quality of Life at Work programs, there are many expectations of results: perception of well-being gain for people, that can influence directly or indirectly the productivity and the financial results of the companies. This study covers the business managers' perception of the evaluation of the results of $Q L W$ programs, based on a quantitative research. It also illustrates these contributions with the case study of SERASA, a Brazilian company that continuously evaluates the results of People Management, presenting the organization's measures for QLW. The conclusions show the needs to develop measures of evaluation, and to emphasize the existence of these measures, as their diffusion is still limitated.
\end{abstract}

\section{KEYWORDS}

Results, people management, management of quality of life at work (QLW), measurement of business results, evaluation of results. 


\section{INTRODUÇÃO}

$\mathrm{O}$ atual contexto social e econômico caracteriza-se por demandar de grande parte das empresas uma crescente atenção com seus ativos intangíveis. Há algumas décadas, a competitividade de várias organizações estava ligada ao tamanho e complexidade de sua estrutura física. Hoje, aspectos como o conhecimento nelas desenvolvido e mantido, sua marca e valorização no mercado, e as pessoas que nelas trabalham podem se tornar diferenciais competitivos mais importantes do que os aspectos tangíveis. Nesta sociedade que Drucker (2000) chama de "Sociedade do Conhecimento", a internacionalização dos mercados e as pressões por produtividade e capacidade competitiva que as empresas vêm sofrendo, tornam cada vez maiores as demandas de produtividade, iniciativa, conhecimento e inovação sobre as pessoas. Estas sentem cada vez mais os efeitos de um novo ambiente de trabalho, onde se exige muito dos profissionais. Assim, a Qualidade de Vida no Trabalho passa a ser uma preocupação cada vez mais presente nas organizações.

Nas organizações e instituições de ensino e pesquisa em Administração de Empresas, as pessoas são o objeto de trabalho e estudo da área de Gestão de Pessoas, mais tradicionalmente denominada Recursos Humanos. Esta é uma área que assume um papel cada vez mais de destaque nas empresas que sofrem mais fortemente a influência da concorrência global e acirrada. Mesmo nas empresas que não possuem um departamento específico, a função de gerir pessoas não deixa de ser executada, e ganha importância para se atingir os objetivos da organização. Esforços de desenvolver as políticas e práticas de gestão de pessoas são muito pertinentes ao momento atual. Um dos campos onde há necessidade de desenvolvimento é o alinhamento das atividades desenvolvidas pela área com os objetivos estratégicos das empresas. Este campo de pesquisa tem sido apontado como um dos mais relevantes neste campo do conhecimento, conforme demonstrou o trabalho de Wright et alli (2001), que fez uma comparação entre as percepções dos executivos do Departamento de Recursos Humanos e dos executivos de outras áreas sobre a eficiência da gestão de pessoas em suas empresas. A pesquisa analisou 14 empresas norte americanas, e trouxe resultados que demonstraram que os executivos de Recursos Humanos acreditavam que a área tem uma eficácia maior do que afirmaram os executivos das demais áreas das empresas. Os pontos de maior divergência entre os dois públicos foram os aspectos diretamente relacionados ao cumprimento das metas da empresa. Como propostas para alinhar a percepção dos executivos sobre a contribuição da área de Recursos Humanos, bem como garantir padrões de qualidade para suas atividades, o estudo sugere a promoção de uma maior integração entre as ações isoladas da área e a estratégia global das empresas e a utilização de ferramentas para avaliar os resultados das práticas de Gestão de Pessoas. A dificuldade de visualização dos resultados das práticas de gestão de pessoas é fruto do grande número de atividades rotineiras que a área exerce em muitas empresas. Para os autores, tais atividades, embora sejam de importância vital para o dia a dia, não garantem necessariamente melhores resultados, principalmente financeiros.

A avaliação dos resultados de Gestão de Pessoas tem um papel importante em ambientes empresariais competitivos, pois instrumentaliza os gestores de negócios e profissionais da área a monitorar as práticas de gestão de maneira a propiciar e monitorar a realização dos objetivos da empresa.

Através da avaliação, consideráveis ganhos podem ser auferidos, como por exemplo, a possibilidade de direcionar os investimentos para os resultados que agregam valor para a organização, alinhando a gestão de pessoas aos objetivos e metas da empresa (Sammartino, 1995). Esse processo pode ser 
otimizado, superando-se alguns obstáculos que a avaliação encontra especificamente nas atividades de Gestão de Pessoas. Tomando-se como exemplo os programas de treinamento, desenvolvimento, Universidades Corporativas, planos de remuneração e de benefícios, Programas de Qualidade de Vida no Trabalho, percebe-se que, muitas vezes, os resultados decorrentes destas atividades não estão ligados de maneira direta com a obtenção de valores financeiros, ao contrário do que ocorre com outras atividades da empresa, como por exemplo, a promoção de vendas.

É difícil relacionar os programas de Gestão de Pessoas aos ganhos que eles trazem para a empresa. Isso faz com que muitos administradores deixem em segundo plano a tarefa de avaliar os resultados do que foi investido. Existe uma falsa crença, muito difundida entre os profissionais, de que os resultados da área não podem ser avaliados, a não ser muito subjetivamente. Conforme afirma Fitz-enz (1984), este mito é uma das causas prováveis porque a prática da avaliação dos resultados é ainda pouco difundida.

Apesar desta aparente restrição cultural, há empresas que êm monitorado as práticas de gestão de pessoas, chegando a coletar dados sobre as operações do dia a dia, tais como o índice de rotatividade de pessoal ou a porcentagem da receita investida em treinamento. Esse monitoramento é importante para controles rotineiros, principalmente com relação a custos, mas estão aquém do esforço necessário para vincular a gestão de pessoas à estratégia organizacional. Para isso, seria preciso utilizar sistemas gerenciais que fossem voltados ao acompanhamento dos objetivos da organização, estabelecendo-se índices para cada objetivo a ser avaliado (Becker, Huselid e Ulrich, 2001). Ainda assim, mesmo o monitoramento das rotinas de pessoal é uma exceção, explicada também pela pouca difusão de ferramentas para se avaliar os resultados da área.

Buscando contribuir para a o desenvolvimento do conhecimento sobre essas ferramentas, o presente estudo discorre sobre a avaliação dos resultados dos programas de Qualidade de Vida no Trabalho (QVT), que representam exemplos de práticas de gestão de pessoas, e que passam, como outras iniciativas da área, pela problemática da avaliação de resultados.

Resultados, neste estudo, são definidos como quaisquer ganhos advindos de programas realizados pelas organizações. São estes os possíveis ganhos financeiros que decorrem indiretamente de programas de gestão de pessoas, bem como outros resultados desejáveis: ganhos de produtividade, diminuição em custos, e finalmente, ganhos em bem-estar para os trabalhadores, ainda mais quando são considerados os Programas de Qualidade de Vida no Trabalho.

Busca-se, neste estudo, responder:

- Qual a percepção dos administradores sobre a avaliação dos resultados das ações e programas de gestão de pessoas, com ênfase nas questões de Qualidade de Vida no Trabalho - QVT?

- Como é realizada a avaliação dos resultados de Gestão dos programas de Qualidade de Vida no Trabalho?

Para responder estas questões, foram utilizadas duas fontes de evidência. A primeira é um recorte teórico da pesquisa exploratória quantitativa realizada por Limongi-França em 2001, respondendo à primeira questão, ou seja, analisando o aspecto referente à percepção dos administradores sobre a avaliação de resultados dos programas de gestão de pessoas, em especial, os de Qualidade de Vida no Trabalho. 
A segunda fonte de evidência é o estudo de caso sobre as práticas da avaliação de resultados desses programas em uma empresa nacional de gerenciamento de crédito. A escolha dessa empresa deve-se ao fato de que ela apresenta boas práticas de avaliação, certificadas pelo Prêmio Nacional da Qualidade (PNQ), que ganhou pela segunda vez, no ano 2000. O PNQ analisa a qualidade da gestão das empresas, englobando diversos critérios de excelência, dentre os quais estão as práticas de gestão de pessoas da organização investigada. Um dos critérios para a premiação é a existência na empresa de formas de avaliação e mensuração dos resultados de suas práticas, inclusive as de gestão de pessoas, e dentre elas, as práticas de Qualidade de Vida no Trabalho. Assim, foi possível incluir neste trabalho os indicadores utilizados pela Serasa ao avaliar a gestão de seus programas de QVT.

\section{A AVALIAÇÃO DE RESULTADOS DE PROGRAMAS DE GESTÃo DE PESSOAS}

A avaliação de resultados de programas de Gestão de Pessoas não é um assunto novo, mas atualmente tem sido pouco investigado de forma científica. Porém há estudos com outros enfoques que podem ser correlacionados com a avaliação de resultados em Gestão de Pessoas. Os estudos sobre a mensuração de ativos intangíveis, proposta por Sussland (2001), e mensuração de resultados de programas de gestão do conhecimento (Skyrme e Amidon, 1998) são importantes referenciais deste tipo de estudo.

Morilha, Albuquerque e Muritiba (2003) apresentam um meta-estudo de trabalhos publicados em caráter nacional (16 trabalhos) e internacional (44 trabalhos), sobre a avaliação dos resultados em gestão de pessoas, no período de 1999 a 2002. A categoria "abordagem temática" foi analisada classificando os artigos em famílias, de acordo com o modo como a avaliação de resultados foi estudada. Foram identificadas cinco categorias de abordagens temáticas, definidas arbitrariamente, conforme os temas que foram surgindo no levantamento dos trabalhos. As famílias identificadas foram:

1) Efeitos da Gestão de Pessoas sobre os resultados das empresas: nesta família, estão agrupados os trabalhos que analisaram os efeitos da gestão de pessoas sobre os resultados das empresas. Dentre os trabalhos que analisam os efeitos da gestão de pessoas sobre os resultados das empresas, destaca-se o trabalho da consultoria Watson Wyatt Worldwide, do Canadá (Brown, 2001), que analisou 750 empresas norte americanas e européias, e mapeou suas práticas de $\mathrm{RH}$, correlacionando-as com o sucesso financeiro das empresas em um estudo longitudinal, de 1999 a 2001.

2) Estratégia de Gestão de Pessoas: artigos que analisam os resultados provenientes da integração entre a Gestão de Pessoas e a estratégia da empresa.

3) Metodologias de Avaliação da Gestão de Pessoas: artigos que propuseram ou analisaram métodos para avaliar a gestão de pessoas das empresas. Merecem destaque, pela originalidade, os trabalhos que propõem metodologias para avaliação de intangíveis, aplicando-as ao caso da gestão de pessoas. Bontis et alli (1999) discorrem de maneira teórica sobre os quatro métodos de mensuração de intangíveis que os autores consideram mais importantes e populares: (1) a contabilidade de recursos humanos; (2) o EVA - economic value added; (3) o balanced scorecard e (4) o conceito de capital intelectual. 


\section{AVALIAÇÃO DA GESTÃo DE PROGRAMAS DE QUALIDADE DE VIDA NO TRABALHO \\ Patrícia Morilha de Oliveira - Ana Cristina Limongi-França}

4) Balanced Scorecard (BSC): artigos que falavam sobre a utilização do Balanced Scorecard para a gestão de pessoas, ou que apresentavam casos de sua utilização. Solomon (2000) apresenta o estudo do caso da GTE, uma empresa do ramo de eletrônicos, que se baseou nos trabalhos de Norton e Kaplan (1996) para modelar seu scorecard aplicado à área de Recursos Humanos, adotando uma abordagem desenvolvida pela própria empresa, e adequada à sua cultura e processos internos.

5) Eficácia da gestão de pessoas: artigos que apresentavam a avaliação de resultados como uma maneira de aumentar a eficácia da função gestão de pessoas na empresa. O trabalho de Lawler III e Mohrman (2000) coloca a avaliação de resultados entre os fatores apontados para eficácia da gestão de pessoas de uma empresa, em uma pesquisa realizada pelo Center of Effective Organizations, destacando a necessidade de se utilizar instrumentos de tecnologia de informação para monitorar os aspectos quantitativos de RH.

Das linhas de pesquisa identificadas acima, dois enfoques agregam a maior parte dos trabalhos sobre a avaliação de resultados. A primeira linha de pesquisa busca indicadores financeiros para demonstrar os resultados da gestão de pessoas, utilizando-se para isso do conhecimento aplicado pela área de finanças para avaliação de ativos diversos. Sobre indicadores, destacam-se os trabalhos de Fitz-Enz (1984; 2001). O autor se dedica há 10 anos ao levantamento de indicadores para se mensurar o retorno dos programas de Recursos Humanos.

Em uma de suas primeiras publicações (1984), o autor aponta alguns dos principais entraves que a avaliação dos resultados em Gestão de Pessoas encontra, e que não dizem respeito necessariamente à natureza subjetiva das atividades dessa função. Ao invés disso, os principais entraves dizem respeito à própria formação do profissional de $\mathrm{RH}$, que muitas vezes, não foi exposto a conhecimentos sobre mensuração e até "teme" utilizar métodos quantitativos, já que a maior parte destes profissionais tem uma formação estritamente humana. O próprio autor é psicólogo, porém utiliza técnicas financeiras e estatísticas para propor os indicadores que utiliza no Instituto Saratoga, do qual é presidente.

Seu mais recente trabalho (2001) utiliza conceitos financeiros para calcular o retorno sobre o investimento (ROI) em Recursos Humanos. O autor propõe uma fórmula para se calcular o valor econômico agregado pelo capital humano. Para isso, ele utiliza o conceito de valor agregado econômico, ou EVA, definido como o lucro operacional líquido após a incidência de impostos, descontando o custo de capital. O objetivo desta medida é determinar se as atitudes da gerência acrescentaram um real valor econômico em vez de simplesmente gerar as demonstrações financeiras típicas, que podem mascarar resultados verdadeiros. O EVA é muito útil, pois revela quanto realmente sobra de lucro, não somente após o pagamento de todas as despesas, inclusive impostos, mas também depois de subtrair o custo do capital investido.

Finalmente, o autor propõe uma equação para se calcular o retorno sobre o investimento em capital humano (Human Capital Return on Investment - HCROI), que considera o retorno no investimento em termos de lucro por quantias de dinheiro despendidas nos ordenados e benefícios dos funcionários.

A fórmula do Human Capital ROI proposta pelo autor é:

$$
\text { HCROI }=\frac{\text { Receita bruta }-(\text { Despesas }- \text { Ordenadose Benefícios })}{\text { Ordenadose Benefícios }}
$$

Nesta equação, ao se subtrair todas as despesas, exceto as relativas aos ordenados e benefícios, obtémse uma estimativa ajustada de lucro. Encontra-se, desta forma, a quantia de lucro obtida por unidade 


\section{AVALIAÇÃO DA GESTÃo DE PROGRAMAS DE QUALIDADE DE VIDA NO TRABALHO}

Patrícia Morilha de Oliveira - Ana Cristina Limongi-França

monetária investida no pagamento do capital humano (não contando treinamento e atividades afins) na realidade, a alavancagem dos ordenados e benefícios.

Uma outra vertente dos modelos propostos por Fitz-Enz (2001) é a medição do impacto do capital humano mos processos. O conceito por trás deste modelo é de que o capital humano tem impacto sobre processos da empresa que constituem uma cadeia valor, onde, no final, é possível calcular economias ou ganhos financeiros. O Quadro 1 ilustra esse raciocínio com exe mplos.

\section{Quadro 1 - Análise do valor do processo}

\begin{tabular}{|c|c|c|c|}
\hline Processo $\longrightarrow$ & Mudança- & Impacto & Valores \\
\hline $\begin{array}{l}\text { Os erros de } \\
\text { faturamento } \\
\text { nas contas a } \\
\text { receber eram } \\
\text { intoleravelme } \\
\text { nte altos }\end{array}$ & $\begin{array}{l}\text { Tela do computador } \\
\text { referente às faturas } \\
\text { redesenhadas e } \\
\text { funcionários do } \\
\text { departamento de } \\
\text { contabilidade treinados }\end{array}$ & $\begin{array}{l}98 \% \text { das faturas } \\
\text { enviadas dentro de } 48 \\
\text { horas do recebimento e } \\
\text { taxas de erros } \\
\text { decresceu para } 1 \% \text {; } \\
\text { menos retrabalho }\end{array}$ & $\begin{array}{l}\text { A idade das contas a receber foi reduzida em } 10 \text { dias; } \\
\text { aumento no fluxo de caixa=US\$ XXX; menos } \\
\text { retrabalho poupa US\$ XXX; menor número de ligações } \\
\text { dos contadores dos clientes melhora a reputação; com } \\
\text { isso, provavelmente, atrai candidatos para posiçõ es } \\
\text { relativas à contabilidade, reduzindo dessa forma o custo } \\
\text { de contratações }\end{array}$ \\
\hline $\begin{array}{l}\text { O tempo de } \\
\text { resposta das } \\
\text { chamadas } \\
\text { para o serviço } \\
\text { ao cliente e } \\
\text { para reparos } \\
\text { dos produtos } \\
\text { era longo } \\
\text { demais. }\end{array}$ & $\begin{array}{l}\text { Redução do tempo de } \\
\text { resposta e tempo de } \\
\text { reparo por meio de um } \\
\text { novo sistema telefônico e } \\
\text { de treinamento para os } \\
\text { profissionais das } \\
\text { assistências técnicas }\end{array}$ & $\begin{array}{l}\text { Queda no número de } \\
\text { reclamações de } \\
\text { clientes, e pesquisa } \\
\text { revelou aumento na } \\
\text { retenção dos clientes. }\end{array}$ & $\begin{array}{l}\text { Despesa com marketing reduzida para conquistar novos } \\
\text { clientes: custo médio para obter um novo cliente = US\$ } \\
\text { XXX economizado. } \\
\text { Cliente satisfeito continua a gastar: vendas médias por } \\
\text { cliente=US\$ XXX. } \\
\text { Indicações de clientes: cada cliente normalmente indica } \\
\text { X novos clientes, que gastam uma média de US\$ XXX. } \\
\text { Não computado: melhora na reputação de mercado, } \\
\text { ocasionando indiretamente novos clientes. }\end{array}$ \\
\hline
\end{tabular}

Fonte: FITZ-ENZ (2001:59)

A segunda linha de pesquisa busca explicações que vão além da ótica estritamente financeira, para analisar a contribuição da gestão de pessoas nos resultados das empresas.

O principal destaque desta linha é o "Balanced Scorecard" aplicado a Recursos Humanos. O Balanced Scorecard consiste em um método de monitoramento das atividades da empresa, por meio de indicadores quantitativos. Este método foi proposto inicialmente por Kaplan e Norton (1996), e posteriormente adaptado à Gestão de Pessoas por Becker, Huselid e Ulrich (2001). Sua premissa é de que a contabilidade tradicional é muito limitada e focada exclusivamente no desempenho financeiro.

Kaplan e Norton (1996) identificaram 4 processos gerenciais críticos às empresas, que não podem deixar de ser avaliados. Eles são: o esclarecimento e a tradução da visão e da estratégia da empresa; a comunicação e associação de objetivos e medidas estratégicas; o planejamento e estabelecimento de metas, alinhando as iniciativas estratégicas e, por fim, o feedback e o aprendizado estratégico. Para os autores, estes quatro processos devem ser medidos e gerenciados. No processo "Aprendizado e crescimento" estão as ações e programas de gestão de pessoas, que visam garantir a capacitação do funcionário para atuar em um processo onde a execução da estratégia traz, por fim, retorno sobre o capital empregado. Isso é demonstrado pelo Esquema 1. 


\section{Esquema 1 - Dimensões a serem avaliadas pelo Balanced Scorecard}

\begin{tabular}{|c|c|c|c|}
\hline Financeira & & $\begin{array}{l}\text { Retono sobre } \\
\text { pital empregado }\end{array}$ & \\
\hline \multirow[t]{3}{*}{ Cliente } & \multicolumn{2}{|r|}{$\begin{array}{l}\text { Leadade dos } \\
\text { Clientes }\end{array}$} & \\
\hline & \multicolumn{2}{|r|}{4} & \\
\hline & \multicolumn{2}{|r|}{\begin{tabular}{|l|} 
Pontualidade \\
\end{tabular}} & \\
\hline \multirow{2}{*}{ Processos Internos } & \multicolumn{3}{|c|}{\begin{tabular}{|c|} 
das Entregas \\
\end{tabular}} \\
\hline & \multicolumn{2}{|l|}{ Processos } & $\begin{array}{l}\text { Ciclos dos } \\
\text { Processos }\end{array}$ \\
\hline Aprendizado e Crescimento & & $\begin{array}{c}\text { Capacidades } \\
\text { do Funcionário }\end{array}$ & \\
\hline
\end{tabular}

Fonte: Kaplan e Norton (1996)

Becker, Huselid e Ulrich (2001) basearam-se na dimensão “Aprendizado e Crescimento" para propor a aplicação do Scorecard à Gestão de Pessoas. Ela pode ser resumida a sete fases cujo objetivo final é garantir que os indicadores definidos pelas empresas estejam coerentes com sua estratégia de negócios. Assim, essa metodologia tem o grande mérito de alinhar a gestão de pessoas da empresa aos objetivos principais de longo prazo da Organização. Esse alinhamento é avaliado por meio de indicadores quantitativos. Os autores trazem 50 possíveis indicadores como exemplos, e que consistem em medidas verificáveis na prática na maioria das organizações, contrariando o senso comum de que é impossível encontrar indicadores mensuráveis de gestão de pessoas.

De acordo com os autores, o modelo do Balanced Scorecard, quando implementado adequadamente, pode trazer vários benefícios para as empresas, dentre eles:

Avaliaria a contribuição de RH para a implementação da estratégia e para os resultados da empresa.

Reforçaria a diferenciação entre rotinas e produtos da área de RH. O sistema de avaliação dos resultados de $\mathrm{RH}$ deve distinguir com clareza entre produtos, que influenciam diretamente a implementação da estratégia, e rotinas, que não exercem efeitos estratégicos.

Capacitaria para o controle de custos e criação de valor. Ao mesmo tempo, Recursos Humanos deve ser uma função que reduz os custos na empresa e que agrega valor para o crescimento da organização.

Permitiria a comparação com indicadores anteriores da área de Recursos Humanos, mantendo, desta maneira, um sistema de avaliação da função RH no tempo.

Os profissionais de Gestão de Pessoas, como qualquer outro profissional da organização, podem valorizar sua posição e a contribuição de seu departamento se puderem comprovar os resultados de suas atividades e sua influência no resultado da Organização. O esforço para formular a avaliação, por si só, já conduz a algumas alterações na maneira de se trabalhar na Organização, na medida em que faz com que os gestores estimem os resultados que desejam obter dos programas (Albuquerque, 1975). 


\section{A Gestão dos programas de Qualidade de Vida no Trabalho (GQVT)}

A melhoria das condições de vida e da saúde tem sido um tema de crescente importância, já que impacta indireta ou diretamente a produtividade das pessoas, e os resultados obtidos pelas organizações. Esse tema tem sido discutido dentro da denominação de Qualidade de Vida no Trabalho (Fernandes \& Gutierrez, 1998). Embora haja um limite sutil entre as questões de trabalho e de vida na família e na comunidade, ambos tratam de questões relacionadas a promover e assegurar a qualidade do bem-estar geral do ser humano. Por isso, tão importante quanto as condições de vida das comunidades são as práticas desenvolvidas pelas empresas, já que é nas empresas que o ser humano desenvolve uma parte muito significativa de sua vida: o trabalho. Segundo Albuquerque e Limongi-França (1998), Qualidade de Vida no Trabalho é um "conjunto de ações de uma empresa que envolve diagnóstico e implantação de melhorias e inovações gerenciais, tecnológicas e estruturais dentro e fora do ambiente de trabalho, visando propiciar condições plenas de desenvolvimento humano para e durante a realização do trabalho".

Neste artigo, os programas de Qualidade de Vida no Trabalho estão sendo estudados no âmbito da gestão de pessoas. Contudo, sabe-se que nem sempre as ações de QVT são desenvolvidas somente por este departamento. Todas as ações que a empresa e os empre gados desenvolvem na busca da integração biopsicossocial e do controle dos fatores de riscos ocupacionais estão ligadas a gestão da qualidade de vida no trabalho. O foco de análise são as ações de QVT desenvolvidas no escopo de Gestão de Pessoas, tais como: atividades associativas e esportivas; eventos de turismo e cultura; atendimento à família; processos de seleção e avaliação de desempenho, carreira, remuneração e programas participativos, que exercem sem dúvida influência sobre a qualidade de vida dos funcionários; medidas ergonômicas e de cuidados com a alimentação.

\section{Aspectos Metodológicos}

Para a realização deste estudo, foram escolhidas como método de trabalho duas fontes de evidência, cada uma delas correspondendo a uma das questões do estudo.

A primeira questão diz respeito a "qual a percepção dos administradores sobre a avaliação dos resultados de gestão de pessoas, com ênfase nos programas de QVT". A metodologia usada para tal questão consiste em um recorte teórico feito em uma pesquisa exploratória quantitativa realizada previamente em um estudo mais amplo. A metodologia utilizada baseou-se no método de pesquisa científica proposto por Selltiz et alli (1974). Este estudo está publicado na íntegra na tese de livredocência de Limongi-França (2001), e seu conteúdo analisa não só questões referentes à avaliação de resultados dos programas de QVT, mas também outras questões sobre a percepção dos administradores sobre esses programas. O perfil dos respondentes foi composto por administradores profissionais, alunos de Administração a partir do $3^{\circ}$ ano, executivos com formação universitária atuando há mais de cinco anos em empresas e professores dos cursos de Administração. Obteve-se 215 questionários válidos, por meio de três procedimentos operacionais: contato direto, contato telefônico e Internet. Em alguns casos, foram utilizados os três procedimentos conjuntamente. Essa diversidade de meios para respostas do questionário permitiu aproveitar os dados da maioria dos entrevistados, já que as dúvidas sobre as respostas foram tiradas pessoalmente ou via contato telefônico. Além disso, favoreceu a obtenção de dados qualitativos, que basearam investigações posteriores. A Internet foi utilizada para distribuição do questionário através do site do Conselho Federal de Administração (www.cfa.org.br) com links na Angrad - Associação Nacional dos Cursos de Graduação em Administração e na Fenead 
- Federação Nacional dos Estudantes de Administração. Foi feito um levantamento por meio de um instrumento composto de 38 questões, utilizando-se uma escala de 1 a 4, dimensionada em pontuação crescente, que avaliava a percepção dos entrevistados sobre as questões colocadas.

A segunda questão diz respeito a "como é realizada a avaliação de resultados destes programas". A segunda fonte de evidência utilizada neste artigo foi a análise de um estudo de caso. Esse método é bastante adequado no caso da avaliação de resultados em gestão de pessoas, campo onde existem relativamente poucas experiência s publicadas (Yin, 1989).

A empresa estudada foi a SERASA, ganhadora, pela segunda vez, do Prêmio Nacional da Qualidade, no ano 2000. O estudo de caso foi realizado com base em dados secundários que constam na Revista Classe Mundial (FPNQ, 2001), que rela ta a experiência da empresa ganhadora trazendo, de maneira bastante completa, a descrição suas práticas de gestão de pessoas e, principalmente, das práticas de avaliação de resultados por ela utilizadas.

\section{RESULTADOS DO ESTUDO EXPLORATÓRIO}

Este artigo descreve o recorte teórico ligado à percepção dos administradores entrevistados sobre a mensuração dos resultados dos programas de QVT.

\section{Perfil dos administradores}

\section{Gráfico 1 - Perfil dos administradores}
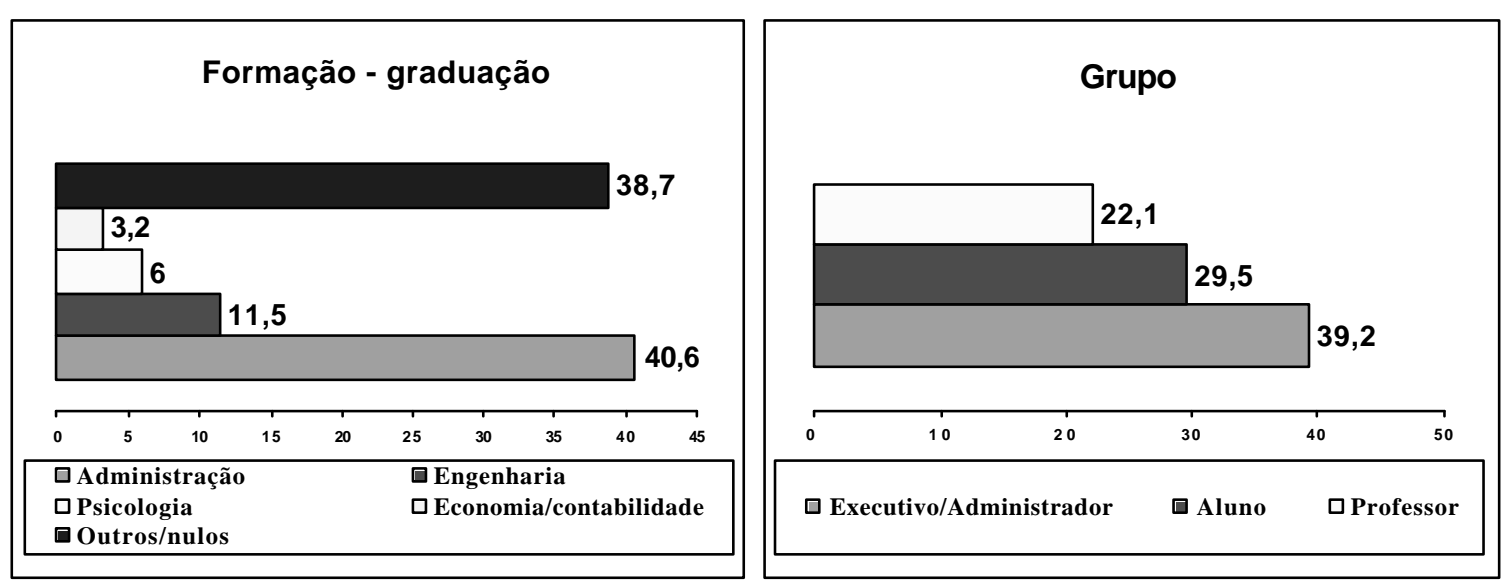

Fonte: Limongi-França (2001) 
Dos 215 participantes da pesquisa quantitativa sobre a qual foi feito o este estudo (Gráfico 1), a maioria consistiu em Administradores (40,6\%), residentes na cidade de São Paulo (82\%), com idade média de 31 a 50 anos (53\%).A maioria dos entrevistados atuava profissionalmente como executivo/administrador $(39,2 \%)$, seguidos os alunos de administração a partir do $3^{\circ}$ ano $(29,5 \%)$ e professores $(22,1 \%)$.

\section{A visão dos administradores sobre a avaliação dos resultados dos programas de QVT}

As questões que analisaram a visão dos administradores sobre a avaliação dos resultados dos programas de QVT mostram que, embora exista a percepção de que não há modelos para se avaliar os resultados desses programas, a maior parte dos entrevistados concorda quanto à existência de resultados mensuráveis dos programas de QVT.

Quando questionados sobre a importância de um programa de Qualidade de Vida no Trabalho, 96,3\% dos participantes afirmaram acreditar que toda empresa deve ter um programa de QVT, ou seja, quase uma predominância absoluta dessa percepção. Isso demonstra a importância geral do tema QVT na administração de empresas. Um grupo de $68 \%$ dos participantes também afirmou que os empregadores consideram necessários as ações e programas de QVT. Um lado negativo desta afirmação é o número de entrevistados que, em contrapartida, acreditam que os empregadores consideram as ações e programas de QVT desnecessários - 32\% dos participantes, o que é uma parcela menor dos entrevistados. É uma porcentagem expressiva, que provoca o questionamento sobre as possíveis causas desta percepção. Para responder a este questionamento, foram analisadas outras questões abordadas pela pesquisa.

Três questões esclarecem esse panorama foram encontradas:

- Há espaço para maior divulgação dos programas de QVT. Os participantes da pesquisa foram questionados sobre terem ou não uma definição clara sobre o conceito de Qualidade de Vida no Trabalho. Uma porcentagem menor, mas bastante significativa, de 35,4\% dos respondentes afirmou não ter definição clara sobre o que seria QVT. Em outras áreas do conhecimento com mais tradição em Administração, a parcela de administradores que não conhecem o conceito seria menor. Isso pode demonstrar que a divulgação dos programas de QVT é ainda incipiente em Administração, provavelmente pelo ineditismo do tema. Essa afirmação é reforçada pela parcela semelhante de pessoas $(35,5 \%)$ que afirmou desconhecer a existência de modelos gerenciais para a implantação de Programas de QVT. Estes dados demonstram, levando-se em consideração as limitações de amostragem, que há espaço para maior divulgação dos programas de QVT.

- Existe a possibilidade de se mensurar os resultados das ações e programas de QVT. Quando questionados se "as ações e programas de QVT interferem positivamente na produtividade", 93,2\% dos participantes responderam que "sim".

- Existe a necessidade de se difundir um modelo de avaliação e mensuração dos resultados de QVT. Esta afirmação, mais ligada ao propósito do presente estudo, foi baseada nas respostas de uma questão da pesquisa exploratória. Os respondentes foram questionados quanto a existência ou não de resultados mensuráveis das ações e programas de QVT. Dentre as respostas válidas, 14,7\% 


\section{AVALIAÇÃO DA GESTÃo DE PROGRAMAS DE QUALIDADE DE VIDA NO TRABALHO}

Patrícia Morilha de Oliveira - Ana Cristina Limongi-França

acreditam que não existem resultados mensuráveis das ações e programas de qualidade de vida no trabalho. Outros $18 \%$ desconhecem tais resultados mensuráveis. A somatória destes dois grupos é um total de 32,7\% dos respondentes que ou não conhecem resultados mensuráveis, ou não acreditam que eles existem. $\mathrm{O}$ desconhecimento de resultados mensuráveis está diretamente ligado à necessidade de se difundir um modelo de avaliação de resultados em QVT, como acontece nas atividades de Gestão de Pessoas em geral. Essa conclusão pode ser sugerida porque, já que 93,2\% dos participantes acreditam que as ações e programas de QVT interferem positivamente na produtividade, então aqueles $32,7 \%$ que desconhecem tais resultados mensuráveis na verdade não foram expostos a ferramentas que mensurassem os resultados que eles sabem que existem.

Desta maneira, é possível concluir que o problema não está relacionado com a falta de resultados mensuráveis, mas sim ao desconhecimento de uma metodologia para se avaliar tais resultados.

Outros possíveis indicadores de que existem resultados mensuráveis em QVT foram apontados ao longo da pesquisa, com grau de concordância médio a alto:

- As ações e programas de QVT são sempre necessárias ao trabalho das empresas (90,7\%). Este é um possível indicador da percepção dos administradores sobre os ganhos conseguidos com a implementação de programas de QVT.

- Empregados valorizam as ações e programas de QVT (85,2\%).

- As ações e os programas de QVT geram benefícios que se perpetuam para sucessores e novas gerações $(82,9 \%)$.

- As ações e programas de QVT devem ser estratégicos (50,2\%).

Uma das questões avaliou os ganhos em produtividade dos programas de QVT mais detalhadamente. A representação gráfica desta questão permite correlacionar as respostas com os indicadores de resultados em Gestão de Pessoas sugeridos por Becker, Huselid e Ulrich (2001). O Esquema 2 apresenta esta correlação.

\section{Esquema 2 - Possíveis indicadores de resultados em QVT}

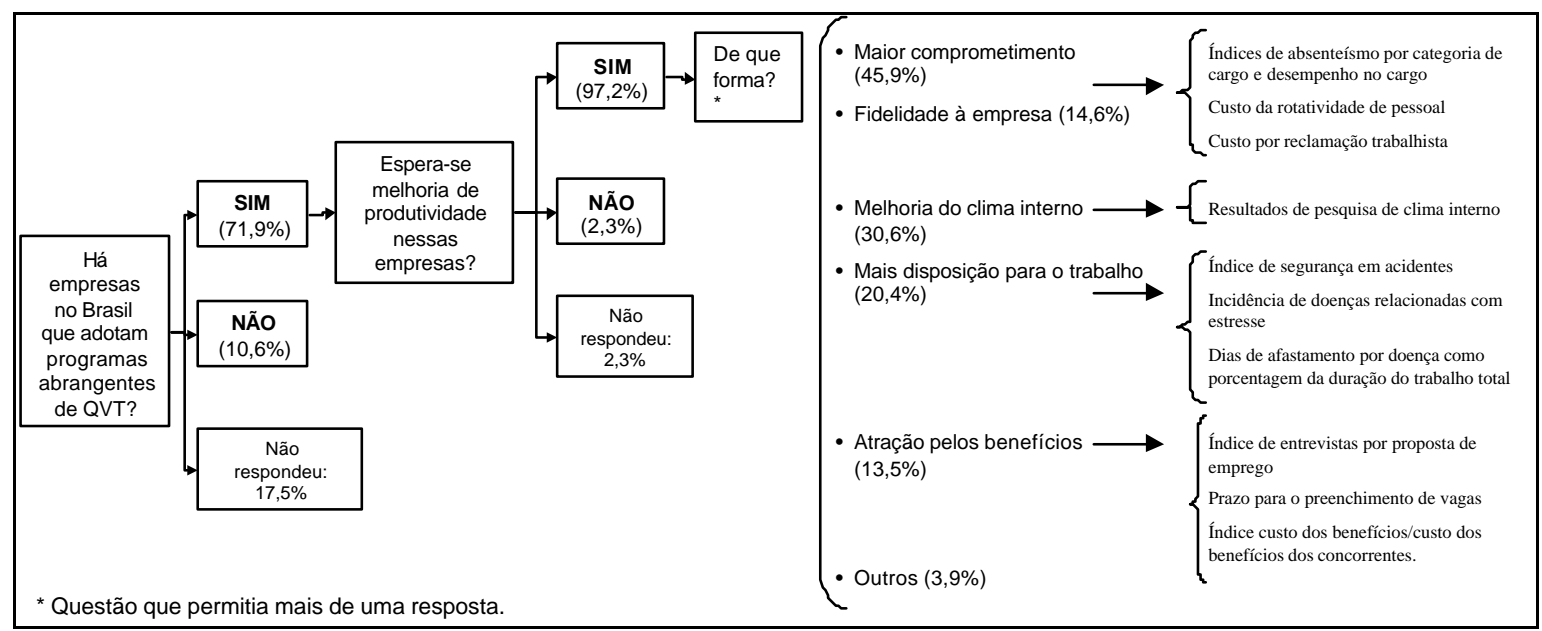

Fonte: dados de pesquisa 
O quadro apresentado ilustra que a percepção geral dos entrevistados é de que a maior parte das empresas brasileiras adota programas abrangentes de QVT. Alguns entrevistados também citaram nomes de empresas que fariam parte deste grupo.

Nestas empresas, é quase uma unanimidade que se espere melhorias de produtividade, que aparecem sob as seguintes formas: maior comprometimento, fidelidade à empresa, melhoria do clima interno, mais disposição para o trabalho e maior atratividade da empresa por causa dos benefícios que ela oferece.

Como uma contribuição, estão sendo relacionados os indicadores propostos por Becker, Huselid e Ulrich (op.cit.) com cada uma das melhorias percebidas pelos participantes, com a intenção demonstrar como se poderia medir e avaliar tais melhorias, em estudos posteriores ou em programas de avaliação de resultados nas empresas. Estes indicadores têm a propriedade de serem facilmente visualizáveis na maior parte das organizações facilitando, assim, o processo de coleta de informações para mensuração.

Há um cuidado essencial a ser tomado quando se pensa em qualquer modelo de avaliação de resultados: o impacto das práticas que se avalia sobre a estratégia e as metas da empresa. No exemplo do quadro acima, supondo que a produtividade não seja essencial para que a empresa agregue valor para seus clientes, mas sim outro fator, como a qualidade da produção (representada pelo menor número de erros possível), então seria mais correto, de acordo com o modelo dos autores, analisar os impactos de QVT sobre a redução de erros, e não sobre a produtividade.

\section{RESULTADOS DO ESTUDO DE CASO: MODELO DE AVALIAÇÃO DE RESULTADOS EM QVT}

Com a finalidade de analisar práticas de avaliação de resultados em QVT, foi realizado o estudo do caso da SERASA, ganhadora do Prêmio Nacional da Qualidade no ano 2000.

\section{Critérios do Prêmio Nacional da Qualidade}

O PNQ - Prêmio Nacional da Qualidade - foi instituído em 1991 pela Fundação para Prêmio Nacional da Qualidade. Desde sua criação, a Fundação conduziu 10 ciclos de premiação do PNQ e entregou 198 relatórios de avaliação para todas as organizações candidatas.

Diversas organizações vêm utilizando internamente os Critérios de Excelência do PNQ, induzindo as melhorias dos seus sistemas de gestão a partir dos resultados advindos da auto-avaliação, inclusive com a criação de premiações internas, como no caso de Furnas, da Petrobrás, da Gerdau, do Serpro, do SENAI, das Delegacias Federais de Agricultura, da Siemens, da Sadia, dentre outras. Os critérios de excelência do PNQ nasceram da observação de empresas bem sucedidas, em meados dos anos 80 . À 
medida que novos valores de gestão de organizações excelentes são desenvolvidos e identificados, os fundamentos da excelência passam por atualizações (FPNQ, 2002).

Os critérios estão divididos em 7 grandes grupos, que formam na verdade um sistema, que tem como resultado a excelência da empresa, caso sejam todos observados.

De acordo com o modelo, as boas práticas de liderança da empresa darão origem a estratégias e planos de sucesso, que deverão ser apoiados por informações e conhecimentos coletados e disseminados na empresa. Essas práticas dão origem e sustentação ao tripé que originará os resultados: a relação da empresa com os seus clientes e a sociedade, apoiada por uma gerência de processos e de pessoas (Esquema 3).

\section{Esquema 3 - Critérios de Excelência do Prêmio Nacional da Qualidade}

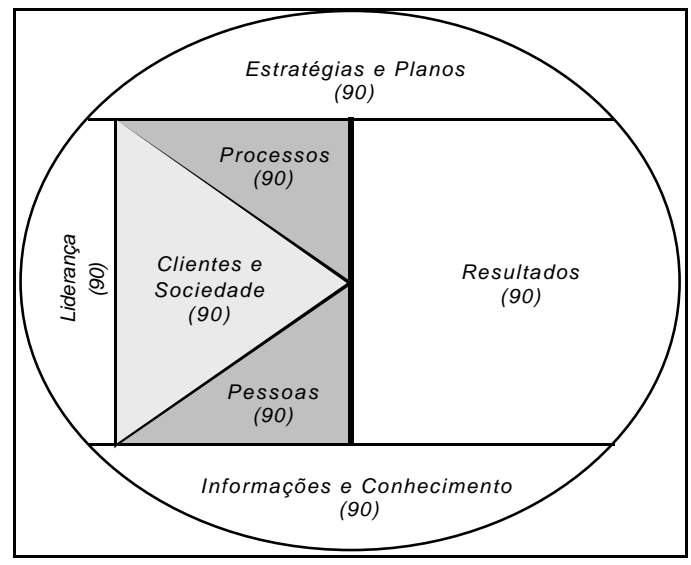

Fonte: Fundação para o Prêmio Nacional da Qualidade, 2002

É importante notar, também, que as empresas ganhadoras do prêmio possuem não só estes critérios muito desenvolvidos dentro da organização, como também instrumentos de mensuração de resultados para cada um dos grandes grupos. A mensuração dos resultados por índices consistentes é um dos fatores que somam pontos na avaliação geral da empresa candidata ao prêmio.

Dentro do critério de excelência "Pessoas" são avaliados indicadores de desempenho dos sistemas de Trabalho, Capacitação e Desenvolvimento, e Qualidade de Vida. Este critério examina como são proporcionadas condições para o desenvolvimento e utilização plena do potencial das pessoas que compõem a força de trabalho, em conjunto com as estratégias organizacionais. O Critério também examina os esforços para criar e manter um ambiente de trabalho e um clima organizacional que conduzam à excelência do desempenho, à plena participação e ao crescimento pessoal e da organização.

As questões avaliadas pelo prêmio no quesito Qualidade de Vida são: como são identificados e tratados os perigos e riscos relacionados à saúde, à segurança e à ergonomia? Como são identificados e tratados os fatores que afetam o bem estar, a satisfação e a motivação da força de trabalho? Como o clima 
organizacional é mantido propício ao bem estar, à satisfação e à motivação das pessoas? Como é verificado se os padrões de trabalho das práticas de gestão relatadas estão sendo cumpridos e como as ações decorrentes são implementadas? Como é feita a avaliação das práticas de gestão e padrões de trabalho deste item? Como as principais inovações ou melhorias decorrentes da avaliação das práticas de gestão e dos respectivos padrões de trabalho são implementadas?

É importante relembrar a relação que existe entre os programas de desenvolvimento e capacitação e a Qualidade de Vida, na medida em que aqueles contribuem para o desenvolvimento pessoal e de maneira indireta para a qualidade de vida dos profissionais, como aponta a pesquisa de Taylor (2000), que correlaciona programas de qualidade total com variações na qualidade de vida dos trabalhadores.

\section{O caso da Serasa}

A SERASA em 1995 conquistou o Prêmio Nacional da Qualidade, repetindo o feito no ano 2000, e foi a primeira empresa de origem brasileira a receber o PNQ, que lhe concedeu o status de Empresa Classe Mundial. A empresa é uma das maiores empresas do mundo em análises de informações econômicofinanceiras e cadastrais para apoiar decisões de crédito e de negócios. Criada em 1968 pelos Bancos para centralizar informações, com o objetivo de racionalizar custos administrativos e obter incrementos qualitativos de especialização, nesta última década estendeu sua atuação para todos os setores da economia.

No aspecto Qualidade de Vida no Trabalho, são muitas as ferramentas e metodologias que visam criar e manter um ambiente de trabalho seguro, saudável e agradável. O processo de Qualidade de Vida é alinhado com o processo da Qualidade Total, e têm o objetivo de proporcionar aos funcionários o gerenciamento de sua saúde e estilo de vida, condições de bem estar pessoal e profissional, melhoria dos relacionamentos interpessoais, visando o equilíbrio entre mente e corpo, desenvolver de forma pró ativa a melhoria da satisfação com o trabalho, melhoria das práticas de saúde e redução de riscos.

A SERASA utiliza as seguintes práticas de avaliação e monitoria dos resultados de seus programas de Qualidade de Vida: realização de fóruns e comitês de atuação executivos e técnicos, com a participação permanente de diretores, superintendentes e gerentes, visando manter a integridade e a flexibilidade da organização, coordenando e avaliando os diversos projetos que estão acontecendo na empresa. Os fóruns e comitês de atuação constituem uma das ferramentas de avaliação qualitativa dos processos organizacionais da organização, inclusive de Gestão de Pessoas. Outras ferramentas qualitativas de avaliação utilizadas são: os grupos de qualidade, formados por voluntários que se reúnem para analisar, entre outros assuntos, melhorias no ambiente de trabalho e questões de qualidade de vida; e a Exposerasa, que consiste em uma feira de reciclagem e aprendizado, criada pela empresa, com o objetivo de apresentar e discutir com funcionários e familiares, entre outros assuntos, programas de desenvolvimento humano e profissional (Qualidade de Vida, treinamento etc.). Os Prefeitos 5S são funcionários, eleitos eletronicamente, que, dentro do seu mandato, ficam responsáveis por monitorar, entre outras questões, as questões de QVT no seu andar. Entre as ferramentas que eles utilizam, podese citar as auditorias internas, que avaliam índices de evolução e retorno do programa.

Em educação e treinamento, questões que contribuem de forma indireta para a qualidade de vida dos funcionários na medida em que permitem seu desenvolvimento pessoal, são avaliados: desempenho real do período, análise de desempenho no trabalho comparada com a análise dos requisitos do cargo e as metas e planos pessoais e profissionais, avaliações de desempenho dos funcionários, comitês de 
Patrícia Morilha de Oliveira - Ana Cristina Limongi-França

avaliação de treinamento. A área de Treinamento é dividida em quatro áreas, com a finalidade de acompanhar os resultados obtidos pelos conhecimentos e habilidades recém adquiridas pelos profissionais.

Além disso, a empresa utiliza indicadores de resultados específicos do programas de saúde e bem estar no trabalho: manutenção de níveis adequados de absenteísmo; rotatividade, colesterol, pressão arterial, diabetes dos funcionários; exames pré admissionais, comparados com exames periódicos, de mudança de função, de retorno ao trabalho e demissionais; Pesquisas de Clima Organizacional; Pesquisas sobre o perfil do Cliente Interno; Pesquisas de Satisfação Pessoal, estratificadas segundo os seguintes fatores de satisfação: imagem da empresa para o funcionário; reconhecimento pelas outras pessoas e áreas; percepção do compromisso com a Qualidade; clareza dos objetivos organizacionais; ambiente físico de trabalho na empresa; integração e comunicação entre pessoas; práticas de gestão de pessoas; estilo gerencial; reconhecimento profissional; clima organizacional - vitalidade; e, por fim, a satisfação em trabalhar na empresa. Os questionários não são identificados, e são ainda analisados por um instituto independente externo, para garantia de maior segurança no processamento dos dados. Os resultados das pesquisas são divulgados pela TV SER SERASA, para envolvimento de todos com as melhorias desejadas. Outras pesquisas específicas são realizadas periodicamente, para questões que envolvem temas definidos, tais como: assistência odontológica, entrevistas de desligamento etc. Também são utilizados índices de existência de greves ou paralisações, problemas sindicais e de reclamações trabalhistas.

A SERASA também possui indicadores para avaliar os resultados gerais da gestão de pessoas da empresa. Eles são avaliados por alguns índices relacionados às práticas de Gestão de Pessoas: (1) Horas de Treinamento/ano por funcionário; (2) Investimento em Treinamento por funcionário; (3) Evolução do número de funcionários, (4) Evolução do Programa de participação nos resultados/despesa total de pessoal; (5) Evolução dos benefícios/faturamento líquido; (6) Evolução do salário nominal médio.

O Esquema 4 toma por base a lógica utilizada no diagrama resultante do estudo exploratório para apresentar, de maneira esquemática, a relação entre práticas relacionadas ao bem estar dos funcionários, indicadores de desempenho utilizados pela SERASA para avaliação destas práticas e, por fim, indicadores de resultados gerais da área de Gestão de Pessoas da empresa. 


\section{Esquema 4 - Instrumentos de avaliação de resultados de QVT da SERASA}

\begin{tabular}{|c|c|c|}
\hline $\begin{array}{c}\text { Práticas relacionadas ao } \\
\text { bem estar no Trabalho }\end{array}$ & $\begin{array}{l}\text { Instrumento de Avaliação } \\
\text { destas práticas }\end{array}$ & $\begin{array}{c}\text { Indicadores de Resultados } \\
\text { da área de RH }\end{array}$ \\
\hline $\begin{array}{l}\text { Programas Gerais de RH, com interface } \\
\text { em QVT } \\
\text { Atuação dos consultores de } \\
\text { Desenvolvimento Humano da empresa } \\
\text { Implementação de equipes } \\
\text { multifuncionais e células de trabalho } \\
\text { Programa Gerente Empresário } \\
\text { Programa Estrategiários } \\
\text { Banco de talentos, Concurso de } \\
\text { Fotografia e Coral } \\
\text { Comemorações de datas } \\
\text { Programas de Treinamento e } \\
\text { Desenvolvimento, com interface em QVT } \\
\text { Educação Corporativa: aplicação de } \\
\text { treinamento, Programa de Integração, } \\
\text { Programa de Relacionamento Interpessoal } \\
\text { (Conhecer Serasa), Programas de } \\
\text { Treinamento em Qualidade } \\
\text { Programas Específicos de QVT } \\
\text { Ações e campanhas de cuidados com a } \\
\text { saúde } \\
\text { Programas de Ergonomia e Ginástica } \\
\text { Laboral } \\
\text { Cursos e palestras de conscientização } \\
\text { (saúde, prevenção de incêndio e primeiros } \\
\text { socorros) } \\
\text { Promoção da saúde } \\
\text { Programa de Prevenção de Riscos } \\
\text { Ambientais }\end{array}$ & $\begin{array}{l}\text { Programas Gerais de RH, com interface } \\
\text { em QVT } \\
\text { Fóruns e comitês de atuação } \\
\text { Grupos de Qualidade } \\
\text { EXPOSERASA } \\
\text { Prefeitos 5S } \\
\text { Níveis de absenteísmo } \\
\text { Níveis de rotatividade de pessoal } \\
\text { Pesquisa de clima organizacional } \\
\text { Pesquisa do cliente interno } \\
\text { Pesquisa de satisfação pessoal } \\
\text { Pesquisas Específicas } \\
\text { Índices de greves, problemas sindicais e } \\
\text { reclamações trabalhistas } \\
\text { Programas de Treinamento } \text { e } \\
\text { Desenvolvimento, com interface em } Q V T \\
\text { Desempenho real do treinamento } \\
\text { Análise do desempenho no trabalho x } \\
\text { análise dos requisitos do cargo x metas e } \\
\text { planos pessoais e profissionais } \\
\text { Avaliaçóes de desempenho dos } \\
\text { funcionários } \\
\text { Comitês de avaliação de treinamento } \\
\text { Divisão da área de treinamento em } 4 \text { sub- } \\
\text { áreas } \\
\text { Programas Específicos de } Q V T T \\
\text { Níveis de colesterol, pressão arterial e } \\
\text { diabetes dos funcionários } \\
\text { Exames médicos (pré-admissionais x } \\
\text { periódicos x demissionais) }\end{array}$ & $\begin{array}{l}\text { Evolução dos Benefícios/Faturamento } \\
\text { Líquido }\end{array}$ \\
\hline
\end{tabular}

Fonte: dados de pesquisa

\section{CONCLUSÃO}

O presente trabalho utilizou duas fontes de evidência para falar sobre a problemática da avaliação de resultados dos programas de Qualidade de Vida no Trabalho - cada uma delas respondendo a uma das questões do estudo.

A primeira questão - "Qual a percepção dos administradores sobre a avaliação dos resultados das ações e programas de QVT?” - foi estudada por meio de um recorte teórico do estudo exploratório 
quantitativo desenvolvido por Limongi-França (2001). Foi contemplada a percepção de 215 administradores sobre a problemática da avaliação de resultados das ações e programas de QVT.

A análise da pesquisa mostrou três principais conclusões acerca da percepção dos administradores sobre os resultados das ações e programas de QVT. A primeira delas é de que é ainda necessário difundir as ações e programas de Qualidade de Vida no Trabalho. Isso foi demonstrado pela existência de uma parcela significativa dos entrevistados que mostrou não ter conhecimentos sobre o conceito de QVT $(35,4 \%)$ e sobre a existência de modelos gerenciais para sua gestão $(35,5 \%)$. A segunda conclusão é de que os administradores vêem a possibilidade de se mensurar os resultados das ações $e$ programas de QVT. Quase todos os participantes da pesquisa $(93,2 \%)$ acreditam que estas ações e programas interferem positivamente na produtividade das empresas. A terceira conclusão, que é a mais significativa para o estudo da avaliação dos programas de QVT é que os administradores sentem a necessidade de se difundir um modelo de avaliação e mensuração dos resultados de Qualidade de Vida no Trabalho. Essa afirmação foi demonstrada por quase um terço $(32,7 \%)$ dos respondentes. Estes acreditam que não existem resultados mensuráveis das ações e programas de qualidade de vida, ou desconhecem tais resultados. Uma análise mais cuidadosa do perfil de resposta desta parcela dos administradores mostra que o problema não é a inexistência de resultados mensuráveis, mas sim, a falta de difusão de métodos para a avaliação desses resultados. Os mesmos 32,7\% que desconhecem tais resultados mensuráveis também afirmaram que as ações de QVT interferem positivamente na produtividade das empresas. Tais resultados positivos são ainda observáveis, de acordo com os participantes, por meio de: maior comprometimento dos funcionários, fidelidade à empresa, melhoria do clima interno, mais disposição para o trabalho e atração pelos benefícios da empresa. Sendo assim, se QVT interfere diretamente na produtividade das empresas, mas seus resultados positivos não são ainda observáveis, fica ressaltada a necessidade de modelos para a mensuração ou avaliação destes resultados. Para ilustrar como estes resultados poderiam ser observados nas empresas, eles foram correlacionados, neste trabalho, com alguns indicadores de mensuração de RH propostos por Becker, Huselid e Ulrich (2001), representados graficamente no Esquema 2.

A necessidade de maior número de opções metodológicas para a avaliação de resultados em gestão de pessoas foi também enfatizada no levantamento teórico, que mostrou a existência de poucas teorias difundidas para esta finalidade. No intuito de contribuir para a difusão de métodos de avaliação de resultados utilizados pelas organizações, foi apresentado o caso da SERASA. A partir do momento em que foram levantados indícios sobre a percepção dos administradores com relação aos programas de QVT, buscou-se respostas para a segunda questão do estudo - "Como é realizada a avaliação de resultados destes programas?".

A SERASA é uma empresa que utiliza várias formas de avaliação para suas práticas de Qualidade de Vida no Trabalho. Elas estão representadas graficamente no Esquema 4. A empresa utiliza dois grupos de indicadores de resultados, representados no quadro citado. O primeiro grupo avalia os resultados da eficiência das práticas de qualidade de vida. Já o segundo grupo complementa esta análise com indicadores dos resultados dos objetivos da área de Gestão de Pessoas. De acordo com o que é preconizado pelos modelos de avaliação de resultados descritos na revisão da literatura, nota-se que, de acordo com as informações obtidas, a SERASA está desenvolvendo bem este aspecto de gestão. Ela utiliza, além de indicadores de desempenho mensuráveis não somente para avaliar a qualidade das práticas de Gestão de Pessoas, também os resultados da área, sejam eles resultados financeiros ou objetivos a serem alcançados. 
A partir deste conjunto de estudos, ratifica-se a necessidade de difusão de práticas para a avaliação de resultados em gestão de pessoas. Existem métodos de grande contribuição, como a adaptação do Balanced Scorecard, proposta por Becker et alii (op. cit.). Destaca-se também o conjunto de indicadores desenvolvidos por Fitz-enz (1984). Estes métodos necessitam de maior difusão e análise crítica entre os administradores de empresas. Uma porcentagem expressiva dos administradores entrevistados pelo estudo sobre Interfaces da QVT na Administração desconhecia metodologias para esta finalidade.

Uma das questões para novos estudos é a discussão acerca de quais resultados são esperados para os programas de Qualidade de Vida no Trabalho, visto que muitas das métricas observadas no caso da SERASA são de caráter operacional ou financeiro; enquanto que, pode-se sugerir que, pelo objetivo dos Programas de QVT em beneficiar a qualidade de vida dos funcionários, poderia-se utilizar também indicadores de bem estar geral das pessoas.

Conclui-se que há recursos metodológicos para se avaliar resultados dos programas de Qualidade de Vida no Trabalho, inclusive os específicos de gestão de pessoas e os desenvolvidos a partir de programas de qualidade e produtividade. No entanto, há necessidade de maior divulgação de métodos, indicadores e ferramentas, gerando práticas e valores efetivos de resultados de gestão alinhados às estratégias empresariais e às condições de vida no trabalho.

\section{REFERÊNCIAS BIBLIOGRÁFICAS}

ALBUQUERQUE, L. G.; LIMONGI-FRANÇA, A. C. Estratégias de Gestão de Pessoas e gestão da qualidade de vida no trabalho: o stress e a expansão do conceito de qualidade total. Revista de Administração, São Paulo, v. 33, n. 2, p. 40-51, Abr./Jun. 1998.

ALBUQUERQUE, L G. Uma abordagem sistêmica ao desenvolvimento de executivos. Dissertação (Mestrado em Administração de Empresas) - Departamento de Administração da Faculdade de Economia, Administração e Contabilidade da Universidade de São Paulo, São Paulo.

BECKER, B. E.; HUSELID, M A.; ULRICH, D. Gestão estratégica de pessoas com Scorecard: interligando pessoas, estratégia e performance. Rio de Janeiro: Campus, 2001.

BONTIS, N.; DRAGONETTI, N. C.; JACOBSEN, K.; ROOS, G. The knowledge toolbox: a review of the tools available to measure and manage intangible resources. European Management Journal, London, Aug., 1999.

BROWN, D. The measure of a function. Canadian HR Reporter, Toronto, Nov. 5th., 2001.

Critérios de Excelência: o estado da arte da gestão para a excelência do desempenho. São Paulo: FPNQ - Fundação para o Prêmio Nacional da Qualidade, 2002

DRUCKER, P. F. Desafios Gerenciais para o Século XXI. 2. tiragem. São Paulo: Pioneira, 2000. 
FERNANDES, E.C.; GUTIERREZ, L H. Qualidade de vida no trabalho (QVT): uma experiência brasileira. Revista de Administração da USP, v. 23, n. 4, p. 29-31-32, Out.Dez. 1998.

FITZ-ENZ, J. Retorno do investimento em capital humano: medindo o valor econômico do desempenho dos funcionários. São Paulo: Mackron Books Ltda, 2001.

FITZ-ENZ, J. How to measure Human Resources management. New York: Mc Graw-Hill Inc, 1984.

KAPLAN, R. S.; NORTON, D. P. Translating Strategy into Action: the Balanced Scorecard. Harvard Business School Press, 1996.

LAWLER III, E.; MOHRMAN, S. A. Beyond the vision: what makes HR effective? Human Resources Planning, Tempe: 2000.

LIMONGI-FRANÇA, A C. Interfaces da Qualidade de Vida no Trabalho na administração de empresas: fatores críticos da gestão empresarial para uma nova competência. Tese (Livre Docência) Departamento de Administração da Faculdade de Economia, Administração e Contabilidade da Universidade de São Paulo, São Paulo.

MORILHA, P.; ALBUQUERQUE, L. G.; MURITIBA, S. N. Uma análise da pesquisa sobre Avaliação de Resultados em Gestão de Pessoas na atualidade. In: ENCONTRO ANUAL DA ASSOCIAÇÃ̃O NACIONAL DE PÓS-GRADUAÇÃO EM ADMINISTRAÇÃO, 2003, Atibaia. Anais. Atibaia: ANPAD, 2003.

Revista Classe Mundial. São Paulo: FPNQ - Fundação para o Prêmio Nacional da Qualidade, v. 1, n 1, Mar. 2001.

SAMMARTINO, W. Influência das políticas e práticas de gestão de Gestão de Pessoas no desempenho organizacional: um estudo de caso na área industrial de uma empresa do setor de elecomunicações. Dissertação (Mestrado em Administração) - Departamento de Administração da Faculdade de Economia, Administração e Contabilidade da Universidade de São Paulo, São Paulo.

SELLTIZ, et al. Métodos de pesquisa nas relações sociais. São Paulo: Editora Pedagógica e Universitária, 1974. [Tradução: Dante Moreira Leite]

SKYRME, D. J.; AMIDON, D. M. New Measures of Success. Journal of Business Strategy, Jan./Feb. 1998.

SOLOMON, C. M. Putting HR on the scorecard. Costa mesa: Workforce, Mar. 2000.

SUSSLAND, W. A. Management through measurement: creating business value through intangibles. Jornal of Business Strategy, Nov./Dec. 2001.

TAYLOR, C. R. Qualidade de Vida no Trabalho: Resultados a partir da implantação de um modelo de Qualidade Total. ENCONTRO ANUAL DA ASSOCIAÇÃO NACIONAL DE PÓS-GRADUAÇÃO EM ADMINISTRAÇÃO, 24., 2000, Florianópolis. Anais. Florianópolis: ANPAD, 2000.

WRIGHT, P. M.; McMAHAN, G C.; SNELl, S. A.; GEHART, B. Comparing line and HR executives' perceptions of HR effectiveness: services, roles and contributions. Human Resource Management, vol. 40, n. 2, p. 111-123, Summer 2001. 
YIN, R. K. Case study research: design and methods in applied social research methods. California: Sage publications, 1989.

Sites rastreados: www.abqv.org.br; www.aparh.com.br; www.cfa.org.br; www.g-qvt.com.br; www.psicossomatica.com.br; www.fea.usp.br; www.usp.br/dedalus.

Artigo recebido em 17.11.2003. Aprovado em 22.07.2004.

\section{Patrícia Morilha de Oliveira}

Doutoranda em Administração de Empresas pela FEA-USP.

Interesses de pesquisa na área de gestão de pessoas.

E-mail:pmorilha@usp.br

Endereço: Rua 23 de Maio, 375, Vila Teresa, São Bernardo do Campo - SP, 09606-000.

\section{Ana Cristina Limongi-França}

Professora da FEA-USP. Pós-Doutoranda da FGV-EAESP.

Interesses de pesquisa na área de gestão de pessoas.

E-mail: climongi@usp.br

Endereço: Av. Prof. Luciano Gualberto, 908, sala E 116, Cidade Universitária, São Paulo - SP, 05508010. 